\title{
PERFORMANCES COTIDIANAS COMO FUNCIONAMENTO LIGADO À VIDA: PRODUÇÃO DO NOVO, DEVIR E...
}

\section{EVERYDAY PERFORMANCES AS AN OPERATION TOWARDS LIFE: PRODUCTION OF THE NEW, AND BECOMING AND...}

Ana Carolina Justiniano ${ }^{1}$

\begin{abstract}
Resumo: Este artigo propõe pensar a performance no campo do educação como um funcionamento ligado à vida, como busca de fôlego em meio a tentativas de explorar e plastificar as incontáveis formas de existência, especialmente no momento atual, em que estamos sob o impacto de forças vorazmente destrutivas (ROLNIK 2018) e assistimos à escalada de forças conservadoras. Em meio a lutas por escapes e busca de ar, percebemos que surgem formas cambiantes de vida e nomadização dos viveres que potencializam os vazamentos metamórficos pelos quais os movimentos curriculares respiram e potencializam a produção do novo (PELBART 2008) bem a potência pulsante de uma educação em devir.
\end{abstract}

Palavras-chave: Performance; educação; devir.

Abstract: This article draws on the notion of performance as an operation connected to life in an attempt to create new modes of existence. It aims at problematizing the invention and creation of new modes of existence as ways to cope with policies that constantly try to freeze modes of life, especially in the Brazilian present context, which is under threat of devastating forces (ROLNIK 2018) as we watch the increase of conservative thinking. As escapes and mutant forms of life come out through, nomadic ways of living and new forms of life emerge in metamorphic and diverse forms that, for their turn, move education towards unpredicted thinking and make it pulse as an education of the becoming.

Keywords: Performance; education; becoming.

Discorremos neste artigo sobre o ímpeto a instaurar outra relação com a vida antes que ela tenha ganhado uma forma, de vidas que 'se livram' de sua 'forma' para dar vazão a re-existências. Entendemos as performances cotidianas na educação como centelhas de vida, como narra Deleuze (2002) no texto Imanência um vida, liberadas quando se está à beira da morte. Mortes que são, de um lado, apresentadas nas políticas unificadoras como a BNCC, a Reforma do Ensino Médio, e de movimentos como o projeto Escola Sem Partido que se de um lado tentam estratificar, por outro lado, provocam, arrastam novos viveres, resistentes, re-existentes em outras formas ao fazer fugir por criações de mundos-outros. Pretendemos provocar o pensar para o fato de que ainda que em meio às sucessivas tentativas de cerceamento, os currículos e as relações nas escolas se abrem em performances cotidianas, nas sutilezas, nos silêncios característicos dos devires (DELEUZE, GUATTARI, 2012a) que deslocam o viver para além de sobreviver, potencializando a criação e redesenhando formas de resistir coletivamente. Produzem-se então, novos fôlegos, novos possíveis a partir dos encontros, forças que escorrem das alianças, do devir, do acontecimento. Partimos da proposição de que nos cotidianos, as performances são produzidas como no ir e vir das marés curriculares e podem nos dar pistas de acoplamentos produzidos nos encontros principalmente em meio a forças conservadoras que tentam incessantemente reduzir a existência a uma "vida besta"2.

\footnotetext{
${ }^{1}$ Universidade Federal do Espírito Santo, Vitória, ES. E-mail: anac.justiniano@ gmail.com.

${ }^{2}$ No texto "Vida nua, vida besta, uma vida" Pelbart (2003) fala da expropriação de várias instâncias da vida pelo poder, reduzindo-a a uma vida besta: a vida resumida ao seu mínimo biológico e transformando os viventes em meros sobreviventes.
} 
Performances que fazem os currículos dobrarem e vazar. Reinvenção de vida dentro da dobra. Linhas do fora que não suportam apenas uma dobra, mas uma multiplicidade de dobras. O que nos instiga na performance é o fato de colocar em risco certezas e verdades que minoram os encontros com multiplicidades de sentidos e de vidas, 'definida' por vários componentes, múltiplas ou multiplicidades em si, irregulares, movidas em velocidades e compostas por heterogêneos. Apostamos que cotidianamente nas escolas e nos currículos, atravessamentos, escapes, colaborações de corpos em fluxos com outros corpos em meio a forças e intensidades mobilizam formas-outras de vida. Pensamos nas performances como linhas de resistência que desafiam o dogmatismo para pensar a diferença como característica e resistir às tentativas de serialização. São, pois, as performances, plurais, resistências redesenhadas com o mudar dos ventos e conexões. Modos de insistir na vida quando formas de viver se travestem em múltiplas formas de ser-estar.

Partimos da performance, não como um conceito estanque, mas como um movimento composto por diversas formas como o borramento de fronteiras (SCHECHNER et al., 2010), desmonte de mecânicas clássicas, desconstrução da representação, um funcionamento ligado à vida, não uma vida encenada, para uma vida para a qual nunca estamos preparados (AGRA, 2012), como a oportunidade de rasurar o que está posto (BOM-TEMPO 2015). Espaço de variação entre vida e arte. Uma vida artistada (CORAZZA, 2002). Uma vida para a qual nunca estamos completamente preparados, pelo contrário, uma vida marcada pelo inacabamento e infinitude.

\section{O que pode a performance em uma educação?}

Embora o campo das Artes ainda seja um lócus privilegiado para as discussões da Performance, sua problematização na arena da educação possibilita falar das variadas formas de se pensar as tensões epistemológicas que aproximaram as performances das questões curriculares.

Dentre as várias problematizações sobre a interface na educação, Schechner et al. (2010) sugerem que a noção de reunião, de encontro e de interação da performance sejam pensadas para potencializar as pesquisas em educação. No mesmo sentido, Icle e Bonatto (2017) apostam em pensar a performance como modo de ensinar e pensá-la como meio para desestabilizar a noção tradicional de escola como local de apagamento do corpo, pela tentativa de silenciamento e contenção corporal que a caracterizam como lugar de produção de sujeitos em experiências performáticas.

Embora estas teorizações tenham movimentado o pensamento curricular para além das prescrições, problematizamos a performance como uma rasura constante, para pensar a escola e o currículo como locais de proliferação de diferença, que, como o rizoma ${ }^{3}$, não se contém. Afastamo-nos, portanto, da Pedagogia Performativa (PINEAU, 2010) que norteia muitas pesquisas que discutem e performance na educação, por percebermos um aceno a um modelo para se pensar a educação, ainda que seja em busca de um "um método para levar a termo a mudança social por meio da educação" (PINEAU, 2010, p. 109). Nossa proposta se afasta das teorizações baseadas na Pedagogia Performativa no sentido em que propomos pensar uma educação provocada pelo encontro com os signos e aberta a experimentações e devires.

Dentre os muitos mundos da escola, somos provocados pela inquietação espinosana $O$ que pode a performance? ao invés de propor métodos. Instigados pela multiplicidade característica dos mundos, nosso objetivo é pensar nas velocidades e lentidões, nas criações e invenções. Nossa aposta é, portanto, nos movimentos sinuosos que se fazem em linhas de fuga, em especial num espaço

\footnotetext{
${ }^{3}$ Um rizoma não começa nem conclui, ele se encontra sempre no meio, entre as coisas, no intermezzo. É unicamente aliança, tem como tecido a conjunção 'e... e... e...'. Desestabiliza o verbo ser. é o lugar onde as coisas adquirem velocidade, como "um riacho sem início nem fim, que rói suas duas margens e adquire velocidade no meio" (DELEUZE; GUATTARI, 2011, p. 49).
} 
como o da escola que embora estriado, é também atravessado por movimentos de (re) (des) territorializações, como lembra Deleuze (2012b) " não só vai do liso ao estriado, mas reconstitui um espaço liso, torna a produzir liso ao final do estriado" (p. 65). Falamos de um espaço esgarçado por forças incompatíveis com receitas de 'como fazer'. Recorremos à performance para problematizar os currículos e sua potência de exterioridade que só existe nas suas próprias metamorfoses, nas suas inovações, invenções, criações, na ocupação de espaços abertos por movimentos turbilhonares que não tem ponto para explodir. Esta premissa inviabiliza a crença num projeto que vise libertação, ou um mundo ideal, dotado de respostas prontas.

Na contramão das fórmulas, Agra (2012) vê no campo da performance uma boa oportunidade para uma invenção do existir, o que acreditamos ser potente, para a tensionar as pesquisas em educação. Uma invenção do existir se faz especialmente, diz Agra, para aquilo que não nos preparamos, nesse sentido, o autor concebe a performance é um 'funcionamento ligado à própria vida' $(2012$, p. 2), não se referindo, obviamente, a uma vida encenada, mas a algo que não estamos, nunca, verdadeiramente preparados “(...) trata-se de uma busca por modos de existência que sejam produtivos para estados de invenção. Se não houver nenhuma certeza quanto a esses modos, ao menos podemos afirmar que, desde já, devem ser, eles mesmos, invenções" (AGRA 2012, p. 3).

Não seria a impossibilidade do preparo um forte indício para pensar uma educação e por conseguinte os currículos da ordem do acontecimento, do devir e produtora da diferença? $\mathrm{Na}$ esteira deste pensamento, Bom-Tempo (2015) vê na performance a possibilidade de colocar em risco uma educação que tende a formatar modos de vida e que produza experimentações e deslocamentos importantes para produção de novas relações com o mundo e com o pensamento.

Embarcamos com Bom-Tempo na aposta por uma educação sujeita a percepções em devires e que produza, parafraseando a autora, pequenos desertos que convocam a criação e movimentos das imagens em performances que mobilizam os signos que formatam os cotidianos, deslocam territórios e abrem os corpos à desorganização e à produção de uma educação dos afetos.

Trazemos a imprevisibilidade e na mobilização de signos de que falam Agra e BomTempo, para pensar a potência da performance como criação de problemas no campo do currículo. Sobre criação de problemas, a partir da obra de Bergson, Deleuze (1999) observa que a noção de problema tem suas raízes na própria vida: "é a vida que se determina essencialmente no ato de contornar obstáculos, de colocar e resolver um problema." (1999 p. 10). Neste rastro, Deleuze afirma que há mais falsos problemas do que falsas soluções e que "(...) o esforço de invenção consiste, geralmente, em suscitar o problema, em criar as condições em que ele será colocado" (idem, p. 9). Um problema já posto retoma uma determinada solução dependendo de como é enunciado, portanto, trata-se de constituir os próprios problemas, suas próprias proposições, criar sua própria sintaxe, seu próprio ritmo.

Afastada da noção de solução para a educação, a performance como criação de problemas nos cotidianos das escolas destitui a ideia de uma educação que produza uniformizações se pensarmos que os problemas são também, produzidos a partir das insurgências cotidianas. Ainda a partir da obra de Bergson, Deleuze (1999) observa que a noção de problema tem suas raízes na própria vida e no impulso vital, portanto, é a vida que se determina essencialmente no ato de contornar obstáculos, de colocar e resolver um problema.

Os falsos problemas são de dois tipos: os inexistentes que concernem a formas de negar a 'verdade' a ordem e o mal colocado. Como exemplo, ele cita a ideia de não-ser como exemplo: não-ser seria a soma da ideia prévia de ser, da operação lógica de negação generalizada quando um ser não nos convém e o apreendemos apenas como falta, ausência do que não nos serve ou interessa. Quando falamos em desordem, estabelecemos a falta da ordem, ou seja, uma regra a priori. $\mathrm{O}$ autor classifica os problemas mal colocados de "mistos mal 
analisados" (DELEUZE, 1999, p. 11) quando se agrupa o que por natureza se difere. Está na tendência que temos, segundo Deleuze (1999), de pensar em termos de mais o menos, ou seja de entender diferenças de grau onde há diferenças de natureza.

Os falsos problemas nos alertam para uma obsessão pelo puro, pelo perigo de medir misturas como unidade. Esta problematização nos convida a pensar as performances nos currículos para escapar da ideia tradicional de que há um vazio a ser preenchido, de que há uma desordem que tenha que se adequar a uma ordem estabelecida, de que o real tenha que realizar uma experiência anterior. Nossa mobilização teórica, não se pretende lutar contra falsos problemas, mas colocar em cheque o movimento retrógrado da verdade sobre o qual Bergson nos alerta e chama de ilusão para percorrer instancias que escapam, e as impurezas que destituem a unidade que é por si só uma mistura e, portanto, impura. Colocar um problema para Deleuze, não é simplesmente descobrir, é inventar. A descoberta não é nosso objetivo porque incide sobre o que já existe, atualmente ou virtualmente, ou seja, cedo ou tarde, diz Deleuze, ela aparecerá. É da ordem do acidente, do devir e do acontecimento.

Não se pretende aqui, descobrir o que é uma performance, o ou que é uma performance cotidiana, mas percorrê-la como invenção, movendo a questão para além das dicotomias e representações do pensamento dogmático que estabelece um universo de problemas dados. Nesse sentido, reiteramos que não pretendemos estagnar a performance em uma definição por acreditarmos, assim como Bom-Tempo (2015) que isto nos afastaria da diferença e do devir. Ao perguntar "o que é uma performance cotidiana?" assumiríamos o "privilégio do 'o que é" (DELEUZE, 2004, p. 113), reforça a autoridade de uma essência e reduz a questão a um diálogo redundante. Provoca o escorregamento na questão formulada diante daquilo que já é dado e desconsidera as diluições e acoplamentos característicos da multiplicidade. O privilégio do "o que é" afasta-nos de uma geografia que convoca um campo problemático que cria a acabaria por provocar congelar o pensamento. $\mathrm{O}$ que nos move, neste artigo, são os movimentos e processos inerentes à potência de micro insurreições e erupções que compõem os cotidianos e que por serem da ordem do imprevisível, são impassíveis de serem enclausurados em denominações hierárquicas e essencialistas.

\section{Plurarizar a performance: a experimentação como direito...}

Por pensarmos na educação e nos processos, assumimos a performance como ideia, como substantivo plural, - portanto, performances- cujo pensamento tem dinamismo próprio. Lançamonos num mar de perguntas em busca de "o que pode?" "qual é o efeito?" "o que é (des)potencializado?" "o que foge?", "o que arrasta?" com o objetivo de escapar de denominações, aprofundamentos e representações nos currículos e suas relações. Cotidianas, as performances como linhas de atualização são formas de invenção, criação de mundos possíveis, seres inacabados, sujeitos nascentes diante das totalizações que tentam enquadrá-los a modelos. Tentamos ventilar as questões curriculares recolocando termos atuais no movimento que os produz nas escolas, relacionando-as às virtualidades que neles se atualizam, para perceber que a diferenciação não é negativa, mas essencialmente positiva e criadora (DELEUZE, 2002). Vemos nas performances a chance de cartografar atualizações que germinam vidas embrionárias e mobilizam um pensamento na educação que destaque o 'inacabamento próprio da vida' assinala Pelbart (2003, p. 12), que salienta que estas questões são prementes, especialmente na educação:

Deveria ser marcante especialmente no âmbito da educação para enxergar em seres que estão por nascer. A experimentação que deveria ser seu direito, na aposta em sua indeterminação, sem coibí-los ou apenas domesticá-los, sem 
insensibilizá-los para tudo aquilo que não serve a nossos desígnios de poder, de pressa, de produtividade, de institucionalidade, com todas suas blindagens e formatações e soluções prontas". (p. 12).

Sublinhamos, assim, a potência do estado de imaturidade da vida que ainda está por nascer, em seres ainda não 'formados' que tem a liberdade ainda preservada mesmo em pequenas mortes que germinam/criam outras vidas, vidas possíveis para não sufocar, pensamos com Deleuze (2010).

Sem a pretensão, como dito antes, de conceituar as performances, exploramos as expansões de vida de que insistem em inaugurar outros modos de ser. Performances, porque não designam. Cotidianas, porque as entendemos como produzidas em encontros potencializados pelos múltiplos afetos nos currículos e por concebermos, a partir de Carvalho (2015), o cotidiano escolar como atravessado por muitos outros contextos e produzido por uma coletividade.

Gallo (2013) problematiza o currículo como "campo de conflitos de resistência e variação" (p. 216) ainda que por outro lado seja também uma máquina de subjetivação que opera de acordo com os desígnios a sociedade capitalística. Com o autor, afirmamos um currículo que se afirma como território constituído que resiste à subjetivação capitalística e reafirma o direito à diferença, à variação e à metamorfose, e acrescentamos, como espaço de devir que se contorce nas escolas que são ao mesmo tempo, ressalta Gallo, aparelhos de Estado como instrumentos para máquinas de guerra.

As performances cotidianas ensejam novas criações, novos possíveis que dão vazão a existências - outras quando se acredita que tudo está perdido. Novamente recorremos a Pelbart (2003) para pensar a produção do novo como "positividade imanente expansiva que o Império insiste em regular, modular, controlar" (p. 23). Na esteira desse pensamento, há processos que irrompem quando a vida diz não à regulação e às forças de assujeitamento que insistem em prevalecer num tempo que as próprias vidas são uma espécie de capital.

Apostamos que este movimento nomádico se estenda às escolas e currículos com a intenção de pensar, no sentido foucaultiano apropriado por Deleuze ${ }^{4}$, como forçar, mover, violentar o pensamento a partir de arrastos e rompantes, nas novas formas de insurreição vital que emergem como novos dispositivos que são permanentemente inventados como produção do novo (PELBART 2003).

Nosso intuito é pensar na criação de vidas que se formam na contramão da serialização e das reterritorializações que nos são sopradas constantemente. Como resposta a tentativas incessantes de "endireitamento", vemos nas performances cotidianas uma espécie de potência da invenção para pensá-las como resistências que passam pela produção de novos desejos, associações e cooperação. Vemos a invenção como ferramenta que forja um novo ser-estar, ambulante, provisório até que determinada 'forma' não seja mais necessária e 'caduque', quando é então arrastada a produzir um novo. Problematizamos ${ }^{5}$ performances cotidianas como processos ambulantes marcados pela infinitude imanente à vida como o intuito de sublinhar as teorizações curriculares que se redesenham por entre mobilizações e resistências reinventadas em e esgarçadas forças turbilhonares.

Evocamos a necessidade de pesquisar formas de ser e estar que não mais se deixam deter nas amarras da antiga lógica de fortaleza, de vidas que não se limitam a sobreviver, mas em reviver nos entrecruzamentos de num trajeto repleto de tentativas constantes de golpeamento e

\footnotetext{
${ }^{4}$ No rastro de Foucault, pensar para Deleuze (2013) é pensar é "estender relações de força, com a condição de compreender que as relações de força não se reduzem à violência, mas constituem ações sobre ações” (p 124). Evocamos com estes autores que o pensamento como estratégia.

${ }^{5}$ Recorremos à noção de Foucault (2010), para o qual problematizar é um gesto investigativo. Implica na produção de outra lógica, da diferença. Trata-se de produzir questões e colocar outras possibilidades de experimentar e desdobrar um conceito em outros.
} 
aprisionamento. Diante dessas vidas que se esgarçam o tempo todo, aprendemos com Foucault (1989) que o próprio controle se dispõe a nomadizar-se, o que torna difícil identificá-lo porque ele se faz rasteiro, cada vez mais pulverizado e imana sobretudo, lembra Pelbart (2003), principalmente das existências mais comuns. Portanto, partimos da aposta na potência de invenção do homem comum, e com Deleuze (2010), afirmamos a criação como uma das mais poderosas formas de resistência. Assumimos com estes autores que criar, portanto, é resistir.

Em resposta às forças supressoras que escamoteiam a potência do homem comum as performances cotidianas nos currículos denotam uma vida política que desafia formas do poder sobre a vida e acabam por criar planos de existência ambulantes. Destacamos a afirmação da vida, política por natureza e dotada de uma energia que nos arrasta a pensar que cotidianamente, as variações nas escolas, ainda que mínimas, ensaiam formas outras de criação como resistência.

Como produção do novo e potência de vida, as performances cotidianas e suas intensidades se emaranham nas relações curriculares, multiplicam-se em linhas, assumem formas de organização novas e são atravessadas por forças num campo múltiplo de produção de desejos e de afirmação das vidas que se (trans) formam à mercê das forças. Pluralizar a performance enfatiza a multiplicidade vital de resistência às tutelas às quais qualquer sujeito está suscetível.

Plurarizamos como forma de conceber a vida que está, definitivamente, politizada, 'apropriada' pelo poder, e, contudo, insiste em re-existir. Sobre esse aspecto, Foucault (1989) alerta que dificilmente resistimos ao poder e acrescenta que seguimos sobrevivendo. Instauramos (sem planejar) planos de fuga, nomadismos, escapes, movimentos de resistência plurais, imprevisíveis que se conjuram na conexão emaranhada entre poder e resistência numa relação de luta, numa provocação permanente.

A tomada do poder sobre a vida é capaz de atravessar seus aspectos mais infinitesimais, de reduzi-la ao seu mínimo biológico embora coexista com certa crise da lógica das fronteiras rígidas. Assistimos a uma nova relação entre o poder e a vida, com as subjetividades que se produzem penetradas, exploradas, fabricadas pelo capital, constituindo, consequentemente o que Pelbart (2003) chama de "uma plasticidade subjetiva sem precedentes, que ao mesmo tempo lhe escapa por todos os lados" (p. 20). Novas subjetividades e potências de vidas são reinventadas e em algum momento, não se deixam aprisionar e explodem.

As performances cotidianas na educação nos forçam a pensar o poder não só como campo de forças manipuladas, calculadas, recalculadas, mas também por forças imprevisíveis. Deleuze (2012 b) nos lembra que uma porta de fuga está sempre ali, presente. Ao falarmos sobre vidas que escapam nos currículos e escolas, falamos de deslocamentos, do poder de afetar e ser afetado. Vidas atravessadas por forças, pois "a vida ao mesmo tempo se pulveriza e se hibridiza, se dissemina, se alastra, se moleculariza e se totaliza" (PELBART, 2003, p. 25). Falamos de relações atravessadas por afetos e cooperação quando surge uma inversão da biopolítica de poder sobre a vida para a potência da vida de afetar e ser afetada para produzir novos incessantemente.

Falamos de currículos que navegam por linhas de diferenciação que só se atualizam por invenção, que não têm a semelhanças como 'regra', mas a divergência e criação. Voltamos a Deleuze (2010) para evocar a potência da atualização e da diferenciação como criação que produzem linhas em constante atualização, divergentes para ressaltar vidas que não operam por metas nem por direções preexistentes, pelo contrário, operam por linhas que são criadas no percorrer da vida.

A própria vida, nos termos de Foucault se torna fator de resistência. Ela se estilhaça e traveste em formas mil. Morre para nascer outra. Mais uma vez, Deleuze nos ajuda a pensar que diante do poder sobre a vida, se constrói, em seus arredores, um poder da vida, uma potência política da vida que faz variar suas fórmulas e reinventar coordenadas. Nos currículos, percorremos performances que se esgarçam num jogo intrincado de um poder que se 
esparramou pela vida, ocupando suas muitas instâncias, calculando e recalculando suas eventualidades e por conseguinte, atualizando-se.

Interessa-nos escapar dos emaranhados que tentam aprisionar a performance em um conceito e empreender por um entendimento que a ressignifique na educação para além do questionamento "o que é" ou "como fazer". Deleuze (2000) reverte a Ideia platônica retirando o maiúsculo inicial da palavra e a colocando-a sobre novo status. Com minúscula, nos desfazemos da Ideia essencial e nos conectamos às ideias e aos acontecimentos e às multiplicidades que surgem em cada pensar e forçam o pensamento às sutilezas dos modos de se agenciamento para que uma ideia aconteça. Não se trata de saber se a Ideia é una ou múltipla, ou as duas coisas ao mesmo tempo, mas de pensá-la como o substantivo: "multiplicidade" intimamente ligada ao acidente e não a uma noção de essência abstrata onde somente questões como $O$ que arrasta? podem determiná-la e traçar suas coordenadas espaço- temporais.

A proposta de Deleuze nos instiga a percorrer a ideia como mote para pensarmos as performances como multiplicidades, em cada pensar uma ideia que força o pensamento às singularidades constituindo um conjunto de determinações imersas em um "(...) campo de individuação, séries de diferenças intensivas, precursor sombrio, acoplamentos, ressonâncias e movimentos forçados, sujeitos larvares, dinamismos espaço-temporais" (DELEUZE, 2002, p. 13).

Fugindo do ímpeto das classificações, nos arriscamos a pensar as performances como 'conceito que diz o acontecimento e não a essência ou a coisa' (DELEUZE, 2010, p. 29), ou seja, não tem um ponto de partida. Infinitude, inacabamento, fragmentação, estado de sobrevoo (DELEUZE 2010). Em hipótese, nos cotidianos escolares surgem como arrasto a partir de um acontecimento definido por heterogêneos, em sobrevoo e velocidade infinita. São relativas por serem mobilizadas a partir de suas relações com outros conceitos, seus acoplamentos, o plano sobre o qual se dão, e ao mesmo tempo, absolutas e fragmentadas pela singularidade, pelo lugar que ocupa sobre o plano, por suas condensações.

Criar em performances cotidianas, plastificar-se, metamorfosear-se como forma de resistência, não só por re-existir no sentido dado por Foucault mas por gerar uma via para criar outros modos de vida nas escolas.

Clareto (2011) fala de um acontecimento produzido nos encontros, que resiste e enfrenta modelos, hegemonias nos métodos de pesquisa na educação para afirmar o campos de pesquisa na educação como um campo metamórfico, híbrido e marcado especialmente pela resistência:

"[...] é resistência: aos processos instituídos de pesquisa, aos modos-bolha de existir. Resistência precária submersa nas águas múltiplas. Resistência: existência monstruosa, híbrida... [...] Existência no labirinto das águas. Experiência no labirinto. Sem saída. Sem entrada. Só entre [...]” (p. 23).

Pesquisar o currículo como campo que ao resiste "inventando águas" (CLARETO, 2011, p. 22), se rabiscando, rasurando fazendo novos como no poema de Alice Ruiz "Chuva no lago... cada gota... um lago novo...". O currículo pensado como um campo-travessia se faz no intermezzo, é um campo-entre, campo-acontecimento: "Acontecimento. Inigualável, inequiparável. Singularidade. Invenção de si e do mundo", como escreve Clareto (2011, p. 23). Campo que se faz onde as coisas ganham velocidade, portanto complexo em meio a planos de composição planos de composição. Esta complexidade nos dá a chance de suspeitar, de acordo com Ferraço et al. (2015) dos "discursos que atribuem aos documentos curriculares oficiais a possibilidade de apagamento da diferença que se manifesta nos cotidianos escolares" (p. 647).

\footnotetext{
${ }^{6}$ Referência aos versos do haicai de Alice Ruiz. De origem japonesa, o haicai é um poema curto, um gênero marcado pelo o extermínio do eu, terminado em reticências.
} 
Queremos ressaltar a complexidade das composições que emergem nos rizomas, povoado por desterritorializações, composto por blocos, multiplicidades, intempestividades. Um currículo afetado pelos ventos, ou seja, não há como, nem porquê sabê-lo. Apenas vivê-lo. Convidamos a pensar os currículos como resistência, mesmo seja difícil pensá-lo desprendido de formas de representação e categorias que enquadram ou dicotomizam.

Nos currículos atravessados por performances cotidianas, ainda que haja dispositivos de poder engendrados, existem em contrapartida, movimentos de reterritorialização e desterritorialização que atravessam esses mesmos processos. Resistência como linha maleável que não designa um embate frontal, violento. Pelas performances cotidianas, seguimos perguntando quais são os fluxos que subvertem, fazem involução, compõem sua própria velocidade, seu ritmo. São as performances cotidianas resistências nômades e moleculares que rasuram currículos, resistências imprevisíveis de potência criadora.

Nos arriscamos a trazer as performances como águas inventadas, para ressaltar a capacidade metamórfica das resistências que se redesenham a partir das relações de mistos. Como produções, cujas intensidades se emaranham e multiplicam em linhas, assumem formas de organização novas e são atravessadas por forças constitutivas do desejo. Num campo de forças múltiplo sob agenciamentos, produção de desejos e de afirmação das vidas que se metamorfoseiam à mercê das devir. Desafiamos-nos a propor uma problematização que pense mundos possíveis como uma multiplicidade vital de resistência às tutelas que qualquer sujeito está suscetível.

Buscamos, pelas performances cotidianas, pensar que corposvida povoam e compõem movimentos infinitos em permanente transformação nos cotidianos que ultrapassam os limites das formas estabelecidas. Sem intenção de ser personificada em alguém ou no efeito de uma ação, elas são mais um acontecimento, mais do que uma ação. Re-existem em um novo que se inaugura e esvanece na imanência de uma vida.

Com João Cabral de Melo Neto (2007, p. 97), seguimos pensando que uma vida jamais se repetirá, tampouco será capaz de estancar a deriva do devir...

E não há melhor resposta
que o espetáculo da vida:
vê-la desfiar seu fio,
que também se chama vida,
ver a fábrica que ela mesma,
teimosamente, se fabrica,
vê-la brotar como há pouco
em nova vida explodida;
mesmo quando é assim pequena
a explosão, como a ocorrida;
mesmo quando é uma explosão
como a de há pouco, franzina;
mesmo quando é a explosão
de uma vida severina.

\section{Referências}

AGRA, Lucio. Contra o adestramento: a performance e outros modos de existência. Revista do Lume, Campinas, n. 2, p. 1-7, 2012. 
BOM-TEMPO, Juliana Soares. Por uma clínica poética: experimentações em riscos nas imagens em performance. 2015. Tese (Doutorado em Educação) - Faculdade de Educação, Universidade Estadual de Campinas, Campinas, 2015.

CARVALHO, Janete Magalhães. O "comunismo do desejo" no currículo. In: FERRAÇO, C. E.; RANGEL, I. S.; CARVALHO, J. M.; NUNES, K. R. (Org.). Diferentes perspectivas de currículo na atualidade. Petrópolis/RJ: De Petrus; Vitória: Nupec/Ufes, p. 79-98, 2015.

CLARETO, Sônia Maria. Na travessia: construção de um campo problemático. In: CLARETO, S. M.; ROTONDO, M. A. S.; VEIGA, A. L. V. S. (Org.). Entre composições: formação, corpo e educação. Juiz de Fora: Editora UFJF, 2011, p. 17-31.

CORAZZA. Sandra Mara. Noologia do currículo: vagamundo, o problemático, o assentado, o resolvido. Educação e Realidade, v. 27, n. 2, p. 131-142, jul./dez. 2002.

DELEUZE, Gilles. Bergsonismo. Trad. Luiz Orlandi. São Paulo: Ed. 34, 1999.

DELEUZE, Gilles. Diferença e repetição. Rio de Janeiro: Graal, 2000.

DELEUZE, Gilles. A imanência: uma vida..., Educação e Realidade, v. 27, n. 2, p. 10-18, jul./dez. 2002.

DELEUZE, Gilles. O método da dramatização. In: DELEUZE, Gilles. A ilha deserta e outros textos. São Paulo: Editora Iluminuras, p. 112-140, 2004.

DELEUZE, Gilles; GUATTARI, Félix. O que é a filosofia? Rio de Janeiro: Ed. 34, 2010.

DELEUZE, Gilles; GUATTARI, Félix. Mil platôs: capitalismo e esquizofrenia, vol. 1. São Paulo: Ed. 34, 2011.

DELEUZE, Gilles; GUATTARI, Félix. Mil platôs: capitalismo e esquizofrenia, vol. 4. São Paulo: Ed. 34, 2012a.

DELEUZE, Gilles; GUATTARI, Félix. Mil platôs: capitalismo e esquizofrenia, vol. 5. São Paulo: Ed. 34, 2012b.

DELEUZE, Gilles; GUATTARI, Félix. Mil platôs: capitalismo e esquizofrenia, vol. 4. São Paulo: Ed. 34, 2012a.

DELEUZE, Gilles. Conversações. São Paulo: Ed. 34, 2013.

FERRAÇO et al. Currículos e culturas: entre clichês e identidades e diferenças e... Currículo sem Fronteiras, v. 15, n. 3, p. 645-666, set./dez. 2015. Disponível em: www.curriculosemfronteiras. Acesso em: 15 jul. 2019.

FOUCAULT, Michel. Microfísica do poder. 8. ed. Rio de Janeiro: Graal, 1989. 
FOUCAULT. Michel. Polêmica, política e problematizações. In: FOUCAULT. M. Ditos \& escritos V: ética, sexualidade, política. Rio de Janeiro: Forense Universitária, 2010, p. 225-233.

GALLO, Silvio. Do currículo como máquina de subjetivação. In: FERRAÇO, C. E.; CARVALHO, J. M. (Org.). Currículos, pesquisas, conhecimentos e produção de subjetividades. Petrópolis/RJ: DP et Alii; Vitória/ES: Nupec/Ufes, p. 203-217, 2013.

ICLE, Gilberto; BONATTO, Mônica Torres. Por uma pedagogia performativa: a escola como entrelugar para professores-performers e estudantes-performers. Cadernos CEDES [Performance e Escola], n. 101, v. 37, p. 7-28. jan.-abr., 2017.

MELO NETO, João Cabral de. Morte e vida severina e outros poemas. Rio de Janeiro: Alfaguara, 2007.

PINEAU, Elyse Lamm. Nos cruzamentos entre a performance e a pedagogia: uma revisão prospectiva. Educação e Realidade, Porto Alegre, v. 35, n. 2, p. 89-113, maio/ago. 2010.

PELBART, P. P. Vida capital. São Paulo: Iluminuras, 2003.

SCHECHNER, Richard; ICLE, Gilberto; PEREIRA, Marcelo de Andrade. O que pode a performance na educação? uma entrevista com Richard Schechner. Educação \& Realidade, Porto Alegre: v. 35, n. 2, p. 23-35, 2010. 